\title{
Calibration of myocardial T2 and T1 against iron concentration
}

John-Paul Carpenter ${ }^{1,2 \dagger}$, Taigang He ${ }^{1,2 \dagger}$, Paul Kirk ${ }^{1,2}$, Michael Roughton ${ }^{1,4}$, Lisa J Anderson ${ }^{3}$, Sofia V de Noronha', A John Baksi ${ }^{1,2}$, Mary N Sheppard ${ }^{1}$, John B Porter ${ }^{4}$, J Malcolm Walker ${ }^{4}$, John C Wood ${ }^{5}$, Gianluca Forni ${ }^{6}$, Gualtiero Catani ${ }^{7}$, Gildo Matta ${ }^{7}$, Suthat Fucharoen ${ }^{8}$, Adam Fleming ${ }^{9}$, Mike House ${ }^{9}$, Greg Black ${ }^{9}$, David N Firmin ${ }^{1}$, Timothy G St. Pierre ${ }^{9}$ and Dudley J Pennell ${ }^{1,2^{*}}$

\begin{abstract}
Background: The assessment of myocardial iron using $T 2^{*}$ cardiovascular magnetic resonance (CMR) has been validated and calibrated, and is in clinical use. However, there is very limited data assessing the relaxation parameters T1 and T2 for measurement of human myocardial iron.
\end{abstract}

Methods: Twelve hearts were examined from transfusion-dependent patients: 11 with end-stage heart failure, either following death $(n=7)$ or cardiac transplantation $(n=4)$, and 1 heart from a patient who died from a stroke with no cardiac iron loading. Ex-vivo R1 and $R 2$ measurements $(R 1=1 / T 1$ and $R 2=1 / T 2)$ at 1.5 Tesla were compared with myocardial iron concentration measured using inductively coupled plasma atomic emission spectroscopy.

Results: From a single myocardial slice in formalin which was repeatedly examined, a modest decrease in T2 was observed with time, from mean ( \pm SD) $23.7 \pm 0.93 \mathrm{~ms}$ at baseline (13 days after death and formalin fixation) to $18.5 \pm 1.41 \mathrm{~ms}$ at day $566(p<0.001)$. Raw T2 values were therefore adjusted to correct for this fall over time. Myocardial R2 was correlated with iron concentration [Fe] $\left(R^{2} 0.566, p<0.001\right)$, but the correlation was stronger between $\operatorname{LnR} 2$ and $\mathrm{Ln}[\mathrm{Fe}]\left(\mathrm{R}^{2} 0.790, \mathrm{p}<0.001\right)$. The relation was $[\mathrm{Fe}]=5081 \cdot(\mathrm{T} 2)^{-2.22}$ between $\mathrm{T} 2(\mathrm{~ms})$ and myocardial iron (mg/g dry weight). Analysis of T1 proved challenging with a dichotomous distribution of T1, with very short T1 (mean $72.3 \pm 25.8 \mathrm{~ms}$ ) that was independent of iron concentration in all hearts stored in formalin for greater than 12 months. In the remaining hearts stored for $<10$ weeks prior to scanning, LnR1 and iron concentration were correlated but with marked scatter $\left(R^{2} 0.517, p<0.001\right)$. A linear relationship was present between $T 1$ and $T 2$ in the hearts stored for a short period $\left(R^{2} 0.657, p<0.001\right)$.

Conclusion: Myocardial T2 correlates well with myocardial iron concentration, which raises the possibility that T2 may provide additive information to T2* for patients with myocardial siderosis. However, ex-vivo T1 measurements are less reliable due to the severe chemical effects of formalin on $\mathrm{T} 1$ shortening, and therefore $\mathrm{T} 1$ calibration may only be practical from in-vivo human studies.

Keywords: Cardiovascular magnetic resonance, Heart, Iron overload, Siderosis, Thalassaemia

\footnotetext{
* Correspondence: d.pennell@ic.ac.uk

${ }^{\dagger}$ Equal contributors

${ }^{1}$ NIHR Cardiovascular BRU, Royal Brompton Hospital, Sydney Street, London SW3 6NP, UK

${ }^{2}$ National Heart and Lung Institute, Imperial College London, London, UK

Full list of author information is available at the end of the article
}

\section{Biomed Central}

(c) 2014 Carpenter et al.; licensee BioMed Central Ltd. This is an Open Access article distributed under the terms of the Creative Commons Attribution License (http://creativecommons.org/licenses/by/2.0), which permits unrestricted use, distribution, and reproduction in any medium, provided the original work is properly credited. The Creative Commons Public Domain Dedication waiver (http://creativecommons.org/publicdomain/zero/1.0/) applies to the data made available in this article, unless otherwise stated. 


\section{Background}

Early detection of cardiac iron is of key importance in the management of patients with transfusion-dependent anaemias, such as beta thalassaemia major (TM). Cardiac siderosis can lead to myocardial dysfunction, heart failure and early death, but it is preventable and potentially reversible with modern chelation regimes $[1,2]$. Prior to the use of Cardiovascular Magnetic Resonance (CMR), it was difficult to identify myocardial iron overload in the pre-clinical phase as measures of body iron loading correlate poorly with myocardial iron [3], and identification of ventricular dysfunction as a clinical expression of cardiac siderosis is usually only late after severe myocardial iron overload is established [4]. T2* CMR has proved to be the most reliable, reproducible and clinically viable method of measuring myocardial iron loading [5-7], with values calibrated to myocardial iron [8], and predictive of cardiac complications [9]. There is evidence that $\mathrm{T} 2 \%$ is superior to other clinical indices (including serum ferritin, liver iron, ventricular ejection fraction, tissue Doppler echocardiographic parameters and endomyocardial biopsy) [4,10-14] and routine application of this technique has been associated with a substantial reduction in deaths from heart failure $[15,16]$.

In the same way that $\mathrm{T} 2 *$ is affected by particulate intracellular iron, the relaxation parameters $\mathrm{T} 2$ and $\mathrm{T} 1$ are also shortened due to local inhomogeneity in the magnetic field, which causes faster proton dephasing [17]. In the liver, $\mathrm{T} 2$ techniques allow accurate assessment of iron loading as well as giving an impression of the degree of hepatic fibrosis present $[18,19]$. In the heart, there has been recent interest in general application of T1 and T2 mapping techniques [20,21], however there remains very limited data in the human heart regarding the relation between $\mathrm{T} 1$ or $\mathrm{T} 2$ and cardiac iron concentration. To extend our knowledge of the effects of myocardial iron on MR relaxation parameters, we measured both T1 and T2 and compared the findings to biochemically derived tissue iron concentration.

\section{Methods \\ Study patients}

This study forms part of a project designed to validate CMR measurement of cardiac iron. Five international centres were involved in recruitment: University College Hospital (London, UK), Ospedale Galleria (Genoa, Italy), The Children's Hospital of Los Angeles (California, USA), Ospedale Regionale Microcitemie (Cagliari, Italy) and Mahidol University (Bangkok, Thailand). In total, 12 whole human hearts were donated for research. These were obtained from patients with transfusion-dependent anaemia either post-mortem or following cardiac transplantation for end-stage heart failure. The study protocol was approved by the Royal Brompton Hospital research ethics committees. Local consent was obtained in all cases.

\section{Study protocol}

All of the hearts were preserved in formalin. All hearts were cut into $1 \mathrm{~cm}$ thick slices in the short axis of the ventricles (Figure 1). The most apical slice was not included in the analysis due to the variation in thickness which could have affected T1 and T2 measurement through partial volume effects. All short axis slices were scanned using a 1.5 Tesla MR scanner (Sonata, Siemens Medical Systems, Germany). Each slice was mounted between two Perspex sheets, immersed in water and scanned using a 4-element phased-array coil. Slices were maintained at a constant $37^{\circ} \mathrm{C}$ throughout.

For T1 measurement, a series of inversion recovery $\mathrm{T} 1$ images was acquired with a range of inversion times $(64,128,256,512,1020,2040,4100$ and $10000 \mathrm{~ms})$, slice thickness $5 \mathrm{~mm}$, flip angle $90^{\circ}$, matrix $128 \times 128$ pixels, sampling bandwidth $230 \mathrm{~Hz} /$ pixel (Figure 2A). For T2 measurement, a series of equally spaced $180^{\circ}$ refocusing pulses were used to generate a train of spin echoes (with 16 echo times (TEs) from 4.8 to $76.8 \mathrm{~ms}$ ). This multiecho fast spin echo T2 sequence had the following parameters: Slice thickness $5 \mathrm{~mm}$, flip angle $90^{\circ}$, matrix $128 \times 128$ pixels, sampling bandwidth $780 \mathrm{~Hz} /$ pixel (Figure 2B). Both sequences were designed to address different ranges of iron loading. Each myocardial slice was scanned in the same orientation to ensure reliable identification of anatomy and wall segmentation for co-localization of decay parameters and iron concentration.

To determine the regions of interest (ROIs) for measurement of T2 and T1, a series of steps were performed as follows. First, endocardial and epicardial borders were drawn for the left ventricle (LV). Then, each myocardial slice was divided into 18 ROIs comprised of outer (epicardial), inner (endocardial) and intermediate (mesocardial) layers in 6 equal radial sectors. The septum was delineated by the attachment of the right ventricular (RV) wall to the LV [22]. T2 was measured from each of the ROIs individually using software specifically designed to quantify signal intensity decay (Thalassaemia-Tools, Cardiovascular Imaging Solutions, London). Where necessary, curve truncation was used to correct for background noise (Figure 2B) [23]. A monoexponential decay curve was fitted using the following equation (where $\mathrm{SI}$ is signal intensity, $\mathrm{SI}_{0}$ is signal intensity at time zero and TE is the echo time):

$$
S I=S i_{0} \cdot e^{-(T E / T 2)}
$$

Analysis of T1 required correction of the phase prior to curve fitting. A T1 recovery curve was then 

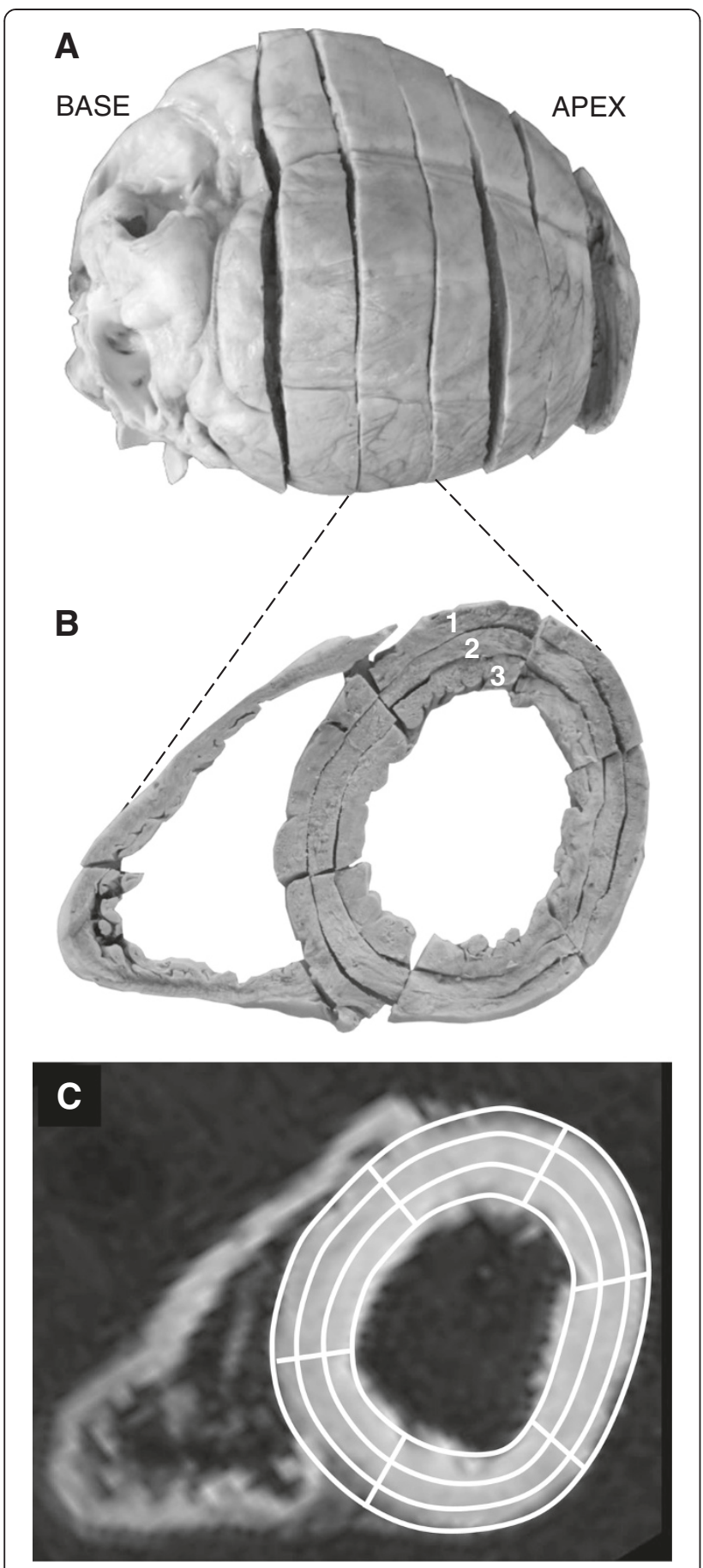

Figure 1 Experimental setup. A. Gross specimen showing $1 \mathrm{~cm}$ myocardial slices from base to apex. B. Mid-myocardial cut slice showing tissue samples. C. Scan image with regions of interest used to measure T2 prior to sectioning.

fitted to the signal intensity points at each time point using a least squares fit (Figure 2A). The signal intensity (SI) at each inversion time is given by the following equation (where TI is the inversion time, $M_{0}$ is the magnetisation and $\mathrm{C}$ is a constant representing noise and artefact:

$$
S I(T I)=M_{0}\left[1-2 \cdot e^{-(T I / T 1)}\right]+C
$$

Any ROIs which contained artefact with the potential to affect T1 or T2 measurement were excluded from the analysis before the measurement was performed.

\section{Effect of formalin on relaxation}

To assess the effect of time in formalin on the relaxation values, a single myocardial slice was scanned at repeated intervals up to 566 days, with measurements in all 18 ROIs at each time point.

\section{Myocardial iron measurement}

After scanning, each short axis LV slice was divided into 18 tissue samples for measurement of iron concentration. Care was taken to ensure that the sections corresponded as closely as possible to the ROIs used for T2 and T1 measurements: 6 sectors of $60^{\circ}$ each, subdivided into 3 transmural layers. Once the wet weight had been recorded, the myocardial tissue blocks were freeze dried in a Virtis type lyophiliser (SP Industries, Inc) for a minimum of 72 hours. Dry weight was recorded immediately after removal from the lyophiliser. Specimens were then placed into plastic digestion flasks along with $10 \mathrm{~mL}$ of $10 \mathrm{M}$ nitric acid $\left(\mathrm{HNO}_{3}\right)$ and heated at $60^{\circ} \mathrm{C}$ for 3 hours on an Environmental Express ${ }^{\mathrm{nex}}$ Hot block. Further heating at $90^{\circ} \mathrm{C}$ for 3 hours was required before removal to a bench to cool for 30 minutes. Addition of $5 \mathrm{~mL}$ hydrogen peroxide $\left(\mathrm{H}_{2} \mathrm{O}_{2}\right)$ was made at room temperature and the solution was then left for an hour to allow bubbling to subside. Samples were returned to the heating block at $60^{\circ} \mathrm{C}$ and allowed to evaporate until nearly dry. Solutions were prepared for iron measurement by adding reverse osmosis purified water to bring the total volume to $30 \mathrm{~mL}$. Iron measurement was performed using inductively coupled plasma atomic emission spectroscopy (ICP-AES). Samples of NIST human liver standard 4352 were used as quality controls for the ICP-AES analysis.

\section{Statistics}

The reciprocals of $\mathrm{T} 1$ and $\mathrm{T} 2$ (R1 and R2) were compared with tissue iron concentration, in common with previous reports of ex-vivo data [8]. Curve fitting was performed by modelling using both linear and nonlinear regression algorithms of raw and log data to determine the best fit. The coefficient of variation for T1 and T2 was calculated independently for each heart. All data were analysed using STATA version 10.1 (StataCorp, Texas, USA). A value of $\mathrm{P}<0.05$ was used to define a significant difference. 


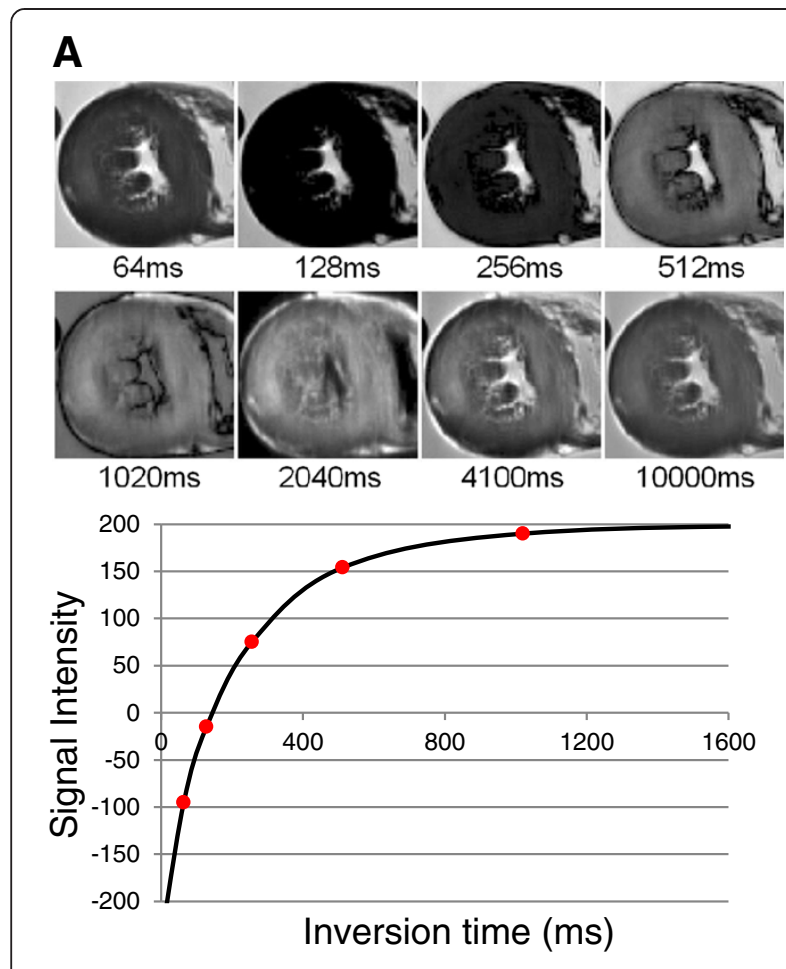

\section{B}
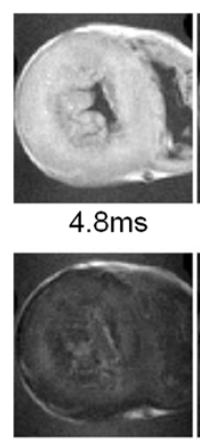

$24 \mathrm{~ms}$

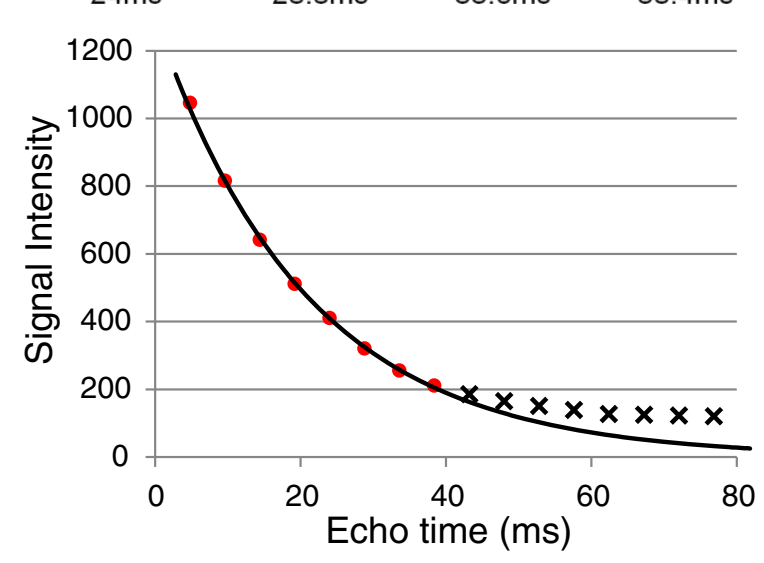

Figure 2 T1 and T2 measurement. T1 and T2 images of the same mid ventricular slice are shown. A. $T 1$ recovery. Following a $180^{\circ}$ inversion pulse, magnetisation recovers to its original value and different myocardial signal intensities are seen in the images taken at a range of inversion times from $64 \mathrm{~ms}$ to 10 seconds (the latter is used to allow magnetisation to fully recover). Myocardial signal is initially negative, recovering through the zero point (where the myocardium appears black) back to its maximal intensity. A least-squares fit allows the calculation of $\mathrm{T} 1$, defined as the time taken for magnetisation to recover $63 \%$ of its original value. B. T2 images showing the initial high myocardial signal which decays over time and the corresponding mono-exponential decay curve of signal intensity plotted against echo time used to calculate T2. The final eight points of the curve have been truncated to allow for background noise.

\section{Results}

Patient details

A total of 12 hearts were donated for this study, with 11 of the hearts from patients who had either died $(n=7)$ or had undergone cardiac transplantation $(n=4)$ for end-stage heart failure. The remaining patient had required lifelong transfusions for beta thalassaemia major but died aged 46 from an ischaemic stroke with no prior cardiac complications, apart from a single short-lived episode of atrial fibrillation at the age of 21. A summary of the clinical information is given in Table 1 .

\section{Comparison of ex-vivo CMR imaging parameters with tis- sue iron}

For 11 of the 12 hearts, mean myocardial iron concentration ranged from 0.38 to $9.5 \mathrm{mg} / \mathrm{g} \mathrm{dw}$. One of the hearts was an extreme outlier with a very high level of iron loading. The mean myocardial iron in this heart was $25.9 \pm 10.3 \mathrm{mg} / \mathrm{g}$, with iron concentrations of up to 100 times the upper limit of normal. The T1 and T2 sequences acquired from this outlier heart suffered from substantial image artefact caused by the sectioning performed at the time of autopsy prior to scanning. Due to difficulty in analysis caused by these artefacts, we considered both T2 and T1 measurements to be unreliable and therefore excluded this heart from the correlation for both parameters. For measurement of T2 and T1, 934 ROIs and their corresponding tissue blocks were used. Some of the remaining hearts had been cut longitudinally at the time of autopsy prior to scanning leading to image artefact at the cut surfaces and as a result, 41 (4.4\%) ROIs were excluded from the T2 analysis and 106 (11.3\%) ROIs were excluded from the T1 analysis.

\section{T1 measurement}

Analysis of T1 proved challenging, with a dichotomous distribution of T1 values. Six of the 11 analysed hearts were found to have extremely short T1 with very little variation between hearts. The mean $\pm \mathrm{SD} \mathrm{T} 1$ value recorded 
Table 1 Patient details, cardiac iron concentration and summary of CMR measurements

\begin{tabular}{|c|c|c|c|c|c|c|c|c|c|c|c|c|}
\hline Patient & Sex & Diagnosis & $\begin{array}{l}\text { Death or cardiac } \\
\text { transplantation }\end{array}$ & $\begin{array}{l}\text { Age at death or } \\
\text { transplantation }\end{array}$ & $\begin{array}{l}\text { Cause of death } \\
\text { or indication } \\
\text { for transplant }\end{array}$ & $\begin{array}{l}\text { LV [Fe] } \\
{[\mathrm{mg} / \mathrm{g} \mathrm{dw}]} \\
(\mathrm{mean} \pm \mathrm{SD})\end{array}$ & $\begin{array}{l}\text { Global myocardial } \\
\text { T1 [ms] (mean } \pm \text { SD) }\end{array}$ & $\begin{array}{l}\text { Variability } \\
\text { of T1 } \\
\text { (CoV\%) }\end{array}$ & $\begin{array}{l}\text { Global } \\
\text { myocardial } \\
\text { T2 [ms] } \\
(\text { mean } \pm \text { SD) }\end{array}$ & $\begin{array}{l}\text { Variability of } \\
\text { T2 (CoV\%) }\end{array}$ & $\begin{array}{l}\text { Total estimated } \\
\text { units transfused }\end{array}$ & $\begin{array}{l}\text { Global } \\
\text { myocardial T2* } \\
\text { [ms] (mean } \pm \text { SD) }\end{array}$ \\
\hline 1 & $M$ & TM & Death & 46 & $\begin{array}{l}\text { Ischemic stroke } \\
\text { (no cardiac failure) }\end{array}$ & $0.38 \pm 0.13$ & $351.4 \pm 37.2$ & 10.6 & $72.7 \pm 7.5$ & 10.3 & 1584 & $44.4 \pm 5.3$ \\
\hline 2 & $\mathrm{~F}$ & SA & Death & 62 & Cardiac failure & $8.20 \pm 1.44$ & $246.1 \pm 37.7$ & 16.0 & $18.6 \pm 2.0$ & 12.3 & 2000 & $4.7 \pm 0.6$ \\
\hline 3 & M & TM & Death* & 10 & Cardiac failure & $9.50 \pm 1.88$ & $93.0 \pm 28.4$ & 30.5 & $14.5 \pm 1.3$ & 8.9 & 170 & $3.7 \pm 0.6$ \\
\hline 4 & $\mathrm{~F}$ & $\mathrm{TM}$ & Death† & 15 & Cardiac failure & $25.9 \pm 10.3$ & - & - & - & - & 288 & $2.0 \pm 0.4$ \\
\hline 5 & $\mathrm{~F}$ & TM & Death & 20 & Cardiac failure & $7.74 \pm 1.51$ & $80.1 \pm 26.0$ & 32.5 & $18.2 \pm 2.4$ & 12.9 & 432 & $3.6 \pm 0.5$ \\
\hline 6 & M & TM & Transplant & 23 & Cardiac failure & $3.63 \pm 0.82$ & $52.3 \pm 13.6$ & 26.1 & $20.3 \pm 1.8$ & 9.0 & 765 & $8.0 \pm 1.0$ \\
\hline 7 & M & TM & Transplant & 24 & Cardiac failure & $3.38 \pm 0.53$ & $68.9 \pm 21.8$ & 31.5 & $21.9 \pm 2.7$ & 12.2 & 528 & $7.7 \pm 1.2$ \\
\hline 8 & M & TM & Transplant & 21 & Cardiac failure & $5.87 \pm 1.0$ & $70.4 \pm 20.1$ & 28.6 & $17.6 \pm 2.1$ & 11.7 & 500 & $4.4 \pm 0.6$ \\
\hline 9 & $\mathrm{~F}$ & TM & Transplant & 31 & Cardiac failure & $8.78 \pm 1.88$ & $68.0 \pm 27.1$ & 39.8 & $13.5 \pm 1.9$ & 14.3 & 624 & $3.9 \pm 0.6$ \\
\hline 10 & M & TM & Death & 24 & $\begin{array}{l}\text { Cardiac failure \& } \\
\text { mucormycosis }\end{array}$ & $5.64 \pm 1.36$ & $247.2 \pm 23.7$ & 9.6 & $24.7 \pm 2.5$ & 10.0 & 660 & $5.8 \pm 1.4$ \\
\hline 11 & M & TM & Death & 44 & Cardiac failure & $3.19 \pm 1.02$ & $305.3 \pm 28.0$ & 9.0 & $43.3 \pm 5.0$ & 11.4 & 1209 & $12.3 \pm 2.6$ \\
\hline 12 & M & DBA & Death & 22 & $\begin{array}{l}\text { Cardiac failure \& } \\
\text { pneumonia }\end{array}$ & $3.91 \pm 0.86$ & $206.4 \pm 26.9$ & 9.5 & $26.8 \pm 3.5$ & 12.7 & 442 & $8.8 \pm 1.8$ \\
\hline
\end{tabular}

$\mathrm{T} 2$ values are time-corrected as described in the text. $\mathrm{SD}=$ standard deviation, $\mathrm{LV}=$ left ventricle, $[\mathrm{Fe}]=$ myocardial iron concentration, $\mathrm{TM}=$ Beta thalassaemia major, $\mathrm{SA}=\mathrm{Sideroblastic}$ anaemia, $\mathrm{DBA}=\mathrm{Diamond}$ Blackfan anaemia, $\mathrm{N} / \mathrm{A}=$ not applicable (patients 3 and 4 did not receive iron chelation therapy: "died 1964; ${ }^{\dagger}$ died 1972). Note hearts $3-9$ were all stored in formalin for over a year prior to scanning. For comparison, global $\mathrm{T}^{*}$ values are shown in the right-hand column. 
from these hearts was $72.3 \pm 25.8 \mathrm{~ms}$ and was independent of tissue iron concentration. This very short T1 recovery was only found in hearts which had been stored in formalin for over a year (heart 3, 5, 6, 7, 8, 9). In the remaining 5 hearts which had been stored for a much shorter duration (less than 10 weeks) prior to scanning, comparison of $\mathrm{R} 1$ and tissue iron revealed a positive correlation but with significant scatter $\left(R^{2} 0.338, p<0.001\right)$. The plot of LnR1 vs $\operatorname{Ln}[\mathrm{Fe}]$ revealed a stronger correlation $\left(\mathrm{R}^{2} 0.517\right.$, $\mathrm{p}<0.001$ ) with a slope of 0.13 [95\% CI: 0.12-0.14] and intercept of 1.19 [95\% CI: 1.17-1.21] (Figure 3A). The representation of this relation on the data scatterplot in linear space is shown in Figure 3B.

\section{Effect of time in formalin on relaxation}

For the single myocardial slice which was examined repeatedly, there was a modest exponential decrease in T2 over time (Figure 4). Mean $( \pm \mathrm{SD}) \mathrm{T} 2$ at baseline (first measured 13 days after death and formalin fixation) was $23.7 \pm 0.93 \mathrm{~ms}$. At day 566 , mean T2 was $18.5 \pm 1.41 \mathrm{~ms}$ $(-21.9 \%, \mathrm{p}<0.001)$. Using an exponential decay model, the effect on T2 measurement in terms of percentage change with time stored in formalin can be expressed by the following equation: Reduction in T2 value over time $(\%)=100-\exp (4.64-0.043 * \ln (t))$ where $t=$ time in days. Only T2 (and not T1) measurements were performed on a repeated basis in view of the unexpectedly low $\mathrm{T} 1$ values identified.

\section{T2 measurement}

In view of the change in $\mathrm{T} 2$ over time and the fact that different hearts had been stored for varying times in formalin, it was deemed necessary to take this into consideration. Therefore, a correction factor was applied to the raw T2 data based on the exponential decay curve from the single stored sample of myocardium as described above. Corrected T2 values were converted to R2 for comparison with [Fe] (Figure 5). Using mean timecorrected R2 for each of the 11 hearts plotted against the mean myocardial iron concentration, a straight line initially appeared a reasonable fit $\left(R^{2} 0.786, p=0.001\right.$, Figure $5 \mathrm{~A}$ ). When all time-corrected $\mathrm{R} 2$ and iron measurements from all samples were considered $(n=893)$, the strongest linear correlation was found by plotting $\mathrm{Ln}$ (time-corrected $\mathrm{R} 2)$ versus $\mathrm{Ln}[\mathrm{Fe}]\left(\mathrm{R}^{2} 0.790, \mathrm{p}<0.001\right)$ giving a slope of 0.45 [95\% CI: 0.44-0.47] and intercept of 3.06 [95\% CI: 3.04-3.09] (Figure 5B). The representation of this relation on the data scatterplot in linear space is shown in Figure 5C. Other analysis models gave less favourable results for correlation coefficient, including simple linear regression $\left(R^{2} 0.566\right)$, and a power function non-linear fit $\left(R^{2}\right.$ 0.593). From the time-corrected log data, the relation between $\mathrm{R} 2, \mathrm{~T} 2$ and myocardial iron
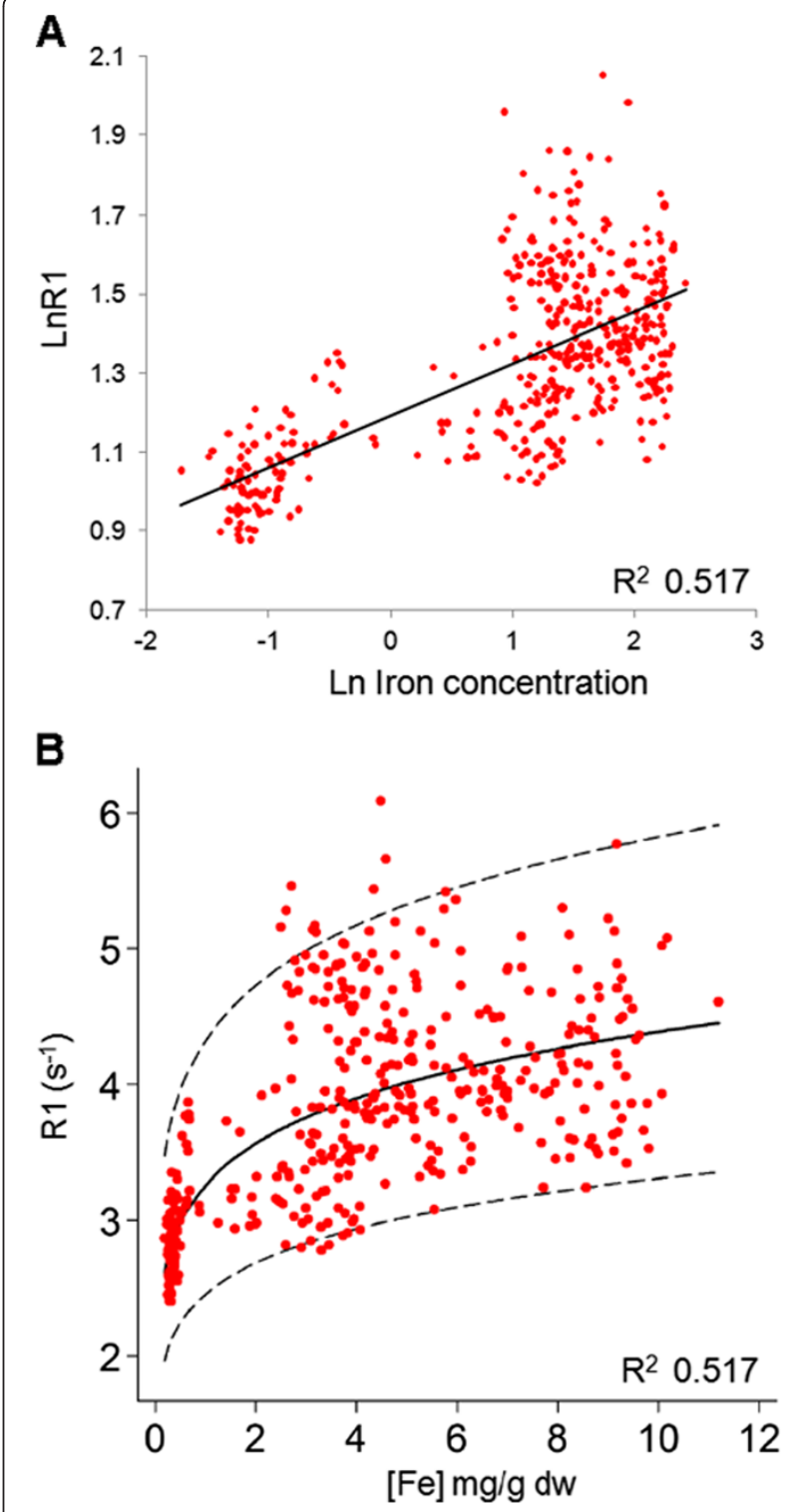

Figure $\mathbf{3}$ R1 and iron concentration. A. LnR1 plotted against Ln [Fe]. The solid line shows the best fit linear correlation for the log data. B. R1 plotted against [Fe]. The solid line represents the correlation derived from the log data shown in A. The dashed lines represent the upper and lower $95 \%$ confidence intervals. Note that these data are for the 5 hearts stored for less than 10 weeks and not all the hearts studied.

( $\mathrm{mg} / \mathrm{g} \mathrm{dw}$ ) can be expressed by the following equation (where R2 is in $\mathrm{s}^{-1}$ and $\mathrm{T} 2$ is in $\mathrm{ms}$ ):

$$
[\mathrm{Fe}]=0.0011 \cdot(\mathrm{R} 2)^{2.22} \text { and }[\mathrm{Fe}]=5081 \cdot(\mathrm{T} 2)^{-2.22}
$$

\section{Relation between $\mathrm{T} 2$ and $\mathrm{T} 1$}

A direct comparison of time-corrected T2 and T1 measurements was made for the 5 hearts which had been 


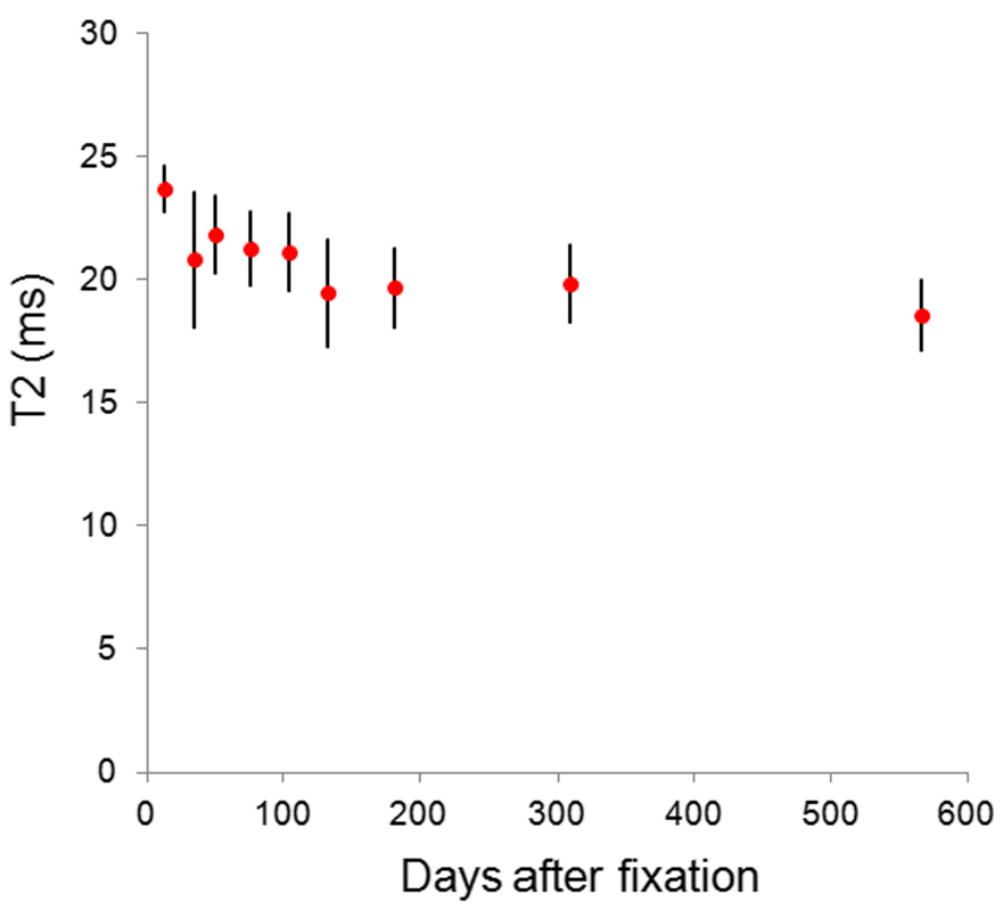

Figure 4 Change in $\mathrm{T} 2$ with time in formalin. 72 measurements plotted against time for a single myocardial slice scanned repeatedly showing a modest fall in T2 with time in formalin. Error bars are \pm SD.

stored in formalin for less than 10 weeks, revealing a linear relation $\left(R^{2} 0.657, \mathrm{p}<0.001\right)$ (Figure 6).

\section{Discussion}

These findings provide new insight into the effects of iron on myocardial MR relaxation parameters. The normal range for iron concentration in myocardial tissue is 0.29-0.47 $\mathrm{mg} / \mathrm{g}$ dry weight [24], and the hearts included in this study have afforded the first opportunity to study myocardial iron loading effects on the MR relaxation parameters $\mathrm{R} 2$ and $\mathrm{R} 1$ over a wide range from the normal range up to fatal iron levels. The results show a strong relationship between $\mathrm{R} 2$ and iron, which is best fitted in our study by a non-linear logarithmic relation. The myocardial curve in this study (Figure 5C) is flatter than that seen for R2 in the liver [18], indicating that using the liver relation could overestimate myocardial iron. The results for R1 were markedly affected by the duration of specimen storage in formalin, and for all hearts which had been fixed $>10$ weeks, all $R 1$ variation in relation to myocardial iron was lost. In the hearts fixed for a short period of $<10$ weeks, the R1 varied with myocardial iron concentration, although this relation was weaker than that observed with R2. Once again, a logarithmic relation best fitted the data for R1, but this would not appear to be clinically useful due to the substantial data scatter and shallow slope. There are potential clinical applications for the measurement of $\mathrm{T} 2$ which remain to be explored, including whether differences in the values of $\mathrm{T}^{*}$ and T2 might yield information about chemical speciation of iron deposits that may have a bearing on iron chelation treatment, and whether T2 might have application in iron mis-handling compartment conditions such as Friedreich's ataxia [25].

Our data on R2 are in broad accord with limited previous data from other groups [26]. In a single post-mortem human heart from a patient with beta-thalassemia major, Ghugre showed that T2 was well correlated at $1.5 \mathrm{~T}$ with myocardial iron concentration [26], but our current results cover a much greater range of iron concentrations. An in-vivo human study by Mavrogeni showed different $\mathrm{T} 2$ values between normal and iron loaded groups using a qualitative assessment of cardiac biopsy iron [27], but this was at $0.5 \mathrm{~T}$ which yields different $\mathrm{T} 2$ values to $1.5 \mathrm{~T}$ and this field strength is not used clinically to assess iron levels. In a gerbil model of siderotic cardiomyopathy, both $\mathrm{T} 1$ and $\mathrm{T} 2$ were related to myocardial iron concentration, with greater variability in T1 measurements than T2 [17]. As already mentioned, when compared with $\mathrm{R} 2$ and iron measured in human liver biopsy samples $[18,19,28]$ our curve appears flatter, but this is consistent with the findings observed in this gerbil model and may reflect the higher water content of myocardium when samples are compared on a dry-weight basis [17].

Despite this observed correlation between myocardial iron concentration and R2, in-vivo measurement can be 

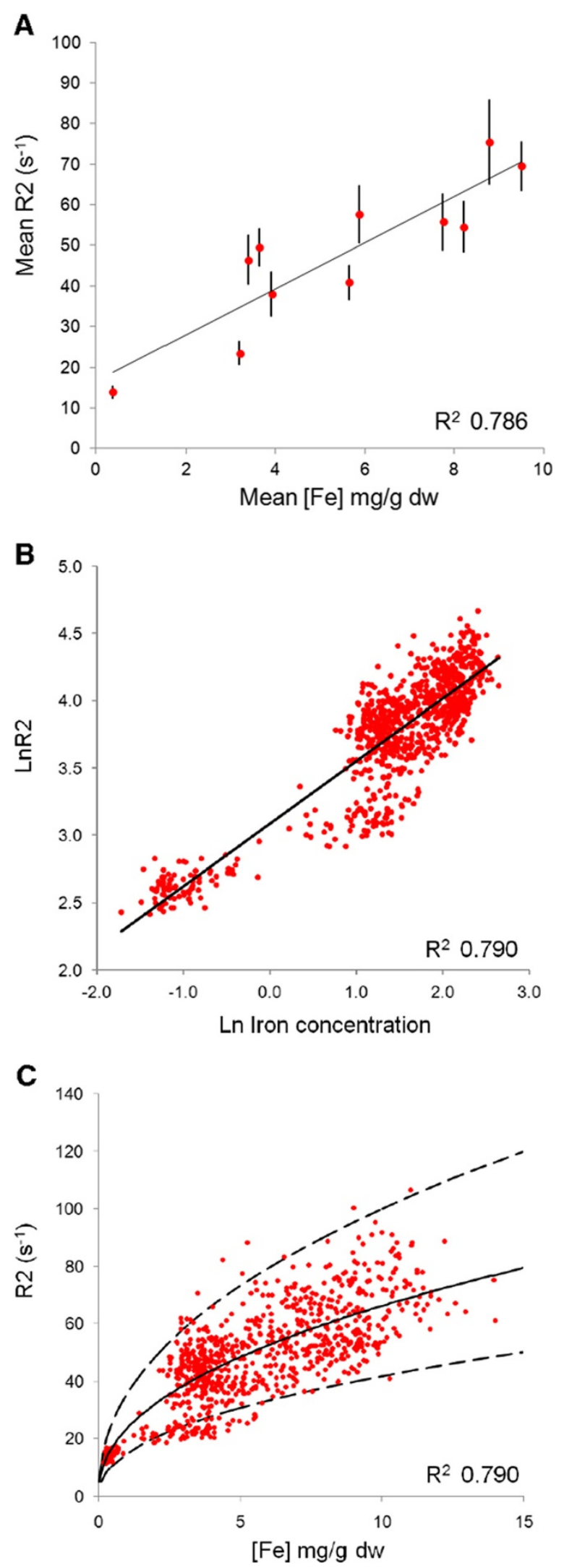

Figure 5 (See legend on next page.) 
(See figure on previous page.)

Figure $\mathbf{5}$ R2 and iron concentration. A. Mean time-corrected R2 plotted against mean iron concentration for each whole heart analysed $(n=11)$. The solid line denotes the linear regression line. Error bars are \pm SD. B. Ln(time-corrected R2) plotted against Ln[Fe] for all myocardial tissue samples $(n=893)$ with the best fit linear regression line. C. Time-corrected R2 values plotted against [Fe] in all samples $(n=893)$. The solid black line is the correlation line derived from the logged data. The dashed lines represent the upper and lower 95\% confidence intervals.

challenging and difficult to apply in a clinical setting $[17,26]$. Recently, a novel CMR method for measuring T2 in the human heart has been developed which gives reproducible results $[29,30]$, and therefore in-vivo comparison of the relative merits of $\mathrm{T} 2$ and $\mathrm{T}^{*}$ measurements is now clinically viable. The situation for R1 measurement is different however. T1-weighted images have previously been used to derive the signal intensity ratio (SIR) between the myocardium and skeletal muscle, but this technique has many potential pitfalls and does not measure T1 decay [31]. The normal expected value for $\mathrm{T} 1$ in human hearts has been determined [32], but there is very little data on the relationship between $\mathrm{T} 1$ and cardiac iron in transfusion dependent patients, and no previous studies have attempted to provide a formal validation for T1, or correlate T1 with tissue iron in human hearts. It remains uncertain therefore whether T1 measurements in TM may have clinical utility, and further insight will need to come from in-vivo studies. From the current study, the measured values for $\mathrm{T} 1$ even in the hearts which had been stored for only a short time in formalin are markedly lower than those measured in patients
[33], and cannot therefore be extrapolated to provide a useful clinical index of iron loading (whether or not this difference is related to the effects of formalin or to differences in the T1 sequences used).

\section{Issues affecting calibration}

The major challenge in providing a definitive calibration for $\mathrm{T} 2$ or $\mathrm{T} 1$ is correcting for differences which exist between in-vivo and ex-vivo magnetic resonance relaxometry measurements. It is important to account for temperature dependence as all the relaxation parameters (T1, T2 and $\mathrm{T}^{*}$ ) show a positive relationship with temperature [34]. Phantom studies have revealed that $\mathrm{T} 2 \%$ can change by up to $1.5 \%$ per degree Celsius [35]. For this reason, in the current study, all of the hearts were scanned at a constant $37^{\circ} \mathrm{C}$ and, with this methodology, we have previously shown that there is very little difference between in-vivo and ex-vivo T2* values [8]. An additional consideration is that artefact affects T2* measurements in-vivo, but this is less of a problem with T1 and T2. For T2\%, susceptibility artefacts are often seen at the myocardial-lung interface, in the inferior wall due to heavy iron loading in the liver,

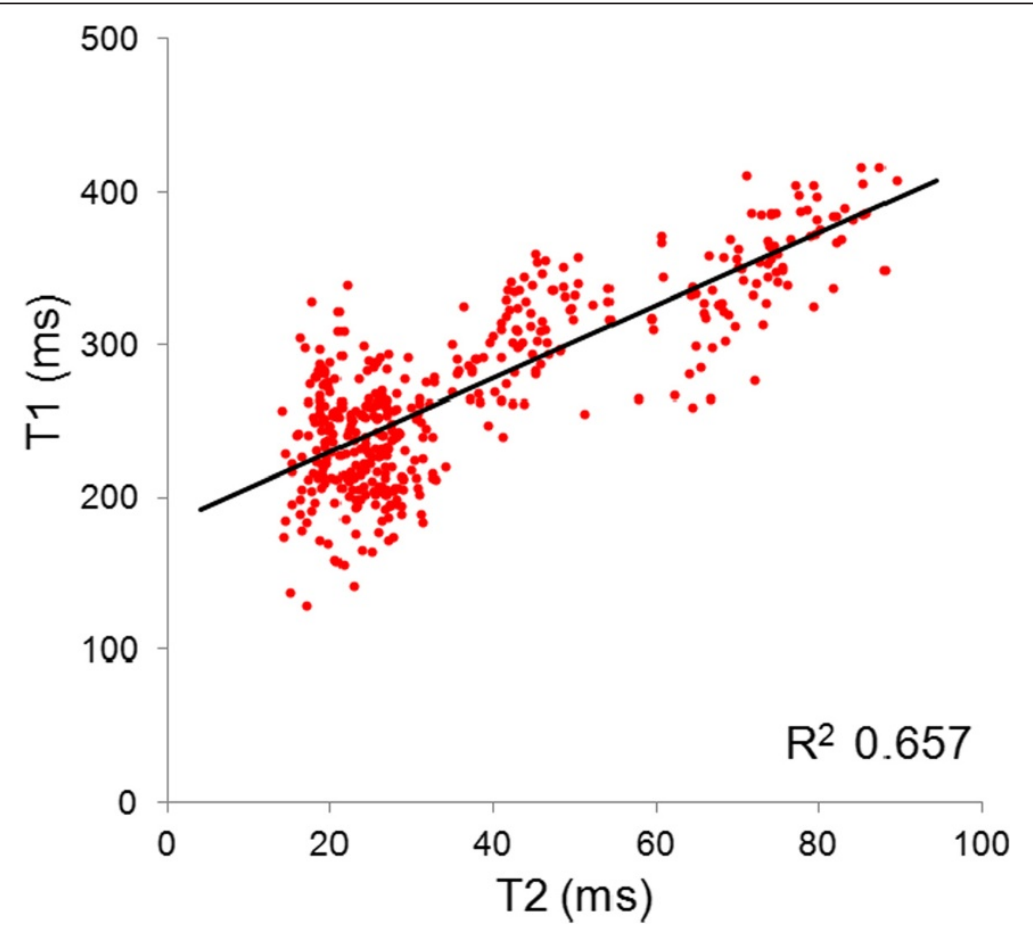

Figure 6 Comparison of T2 and T1. T1 plotted against time-corrected T2 in the myocardial samples from the 5 hearts which were stored in formalin for $<10$ weeks. The linear regression line is shown. 
as a result of cardiac motion, and from veins in the atrioventricular groove containing deoxygenated blood. Although blood oxygenation level affects $\mathrm{T} 2 *$ in vivo, $\mathrm{T} 1$ and $\mathrm{T} 2$ are less affected and in any case, this is unlikely to affect post-mortem $\mathrm{T} 1$ or $\mathrm{T} 2$ values [36].

The non iron-loaded heart in the current study had a mean \pm SD $\mathrm{T} 1$ value of $351.4 \pm 37.2$ and a mean $\mathrm{T} 2$ value of $63.4 \pm 6.5 \mathrm{~ms}$. Normal myocardial T1 measured in vivo is much higher, in the order of $1100 \mathrm{~ms}$ [37]. A previous study looking at $\mathrm{T} 1$ of formalin fixed infarcted myocardium stored for between 1 and 9 years, found significantly shorter T1 values with a T1 of $272 \pm 163 \mathrm{~ms}$ in non-infarcted tissue and $459 \pm 266 \mathrm{~ms}$ in infarct tissue [38]. Some previous evidence suggests that while organ iron concentration is lower after fixation in formalin or histological processing, the difference is not significant $[39,40]$. In comparison, immersion in saline causes a significant drop in tissue iron levels with up to $50 \%$ lost in the first hour [41]. Although very little iron is lost from cardiac tissue stored in formalin after the first 60 days [42], there appears to be a marked change in the T1 properties of our stored samples with prolonged storage. The fact that a very short T1 (independent of iron concentration) was found in all the hearts which had been stored in formalin for greater than a year, suggests that the T1 shortening effect was likely to be due to the effects of formalin, but the precise reasons for this remain unclear. T2 in formalin-fixed myocardium is less affected but is also slightly shorter than the normal in-vivo level (which is around $70 \mathrm{~ms}$ ) [38,43].

The ideal fixative agent would not alter the biological, physical or paramagnetic properties of the tissue concerned. Formalin, however, causes initial shrinkage followed by swelling of cells over the first hour, which then return to their original size. There is rapid hardening of tissues and also loss of water. T1 is highly dependent on the water content of the tissue, and thus T1 falls following fixation [44], however the relationship between T2 and water content does not have the same predictable effect [34]. Formalin molecules may form covalent and ionic bonds within tissues, predominantly with amino groups. Thus, as changes in structure and proton mobility occur together with dehydration and denaturation of proteins, proton relaxivity is affected with consequent changes in $\mathrm{T} 1$ and $\mathrm{T} 2$ [45]. Initial changes in $\mathrm{T} 1$ seem to occur more quickly in some tissues than in others, possibly due to the effects on phospholipid structure [46]. There is conflicting data in rat liver and spleen samples, where a significant decrease in $\mathrm{T} 1$ but initial elevation in $\mathrm{T} 2$ has been observed following fixation [47]. Mathematical modelling has been used to assess changes in $\mathrm{T} 1$ and $\mathrm{T} 2$ in the human brain after formalin fixation [48]. Relaxation maps confirm progressive $\mathrm{T} 1$ and $\mathrm{T} 2$ shortening with time and findings from this model suggest that the brain is not completely saturated in formalin until after 14.8 weeks of immersion. Changes in $\mathrm{T} 1$ and $\mathrm{T} 2$ are not complete until after 5.4 weeks, although the effects on fixed myocardial tissue may take longer. The chemical form of iron however, appears to remain constant. Mössbauer spectra of freeze-dried tissue in human spleen, liver and pancreas samples reveal no evidence of chemical transformation of iron after immersion in formalin for 200 days [42]. For splenic tissue, the ratio between heme iron and non-heme iron has been observed to differ between fresh and formalin-fixed samples, but this finding was considered to represent inhomogeneity of iron loading within the spleen itself rather than a true alteration in chemical form [42].

\section{Limitations}

The main limitation of this study is the relative change in T2 and T1 following formalin fixation. This is discussed above, but dominantly affects T1 values. None of the patients underwent T2 or T1 measurement pre-mortem and T1 values were not measured over time. Therefore, we cannot confirm whether there are significant changes in $\mathrm{T} 2$ or T1 post-mortem following formalin fixation compared to their pre-mortem values. Notwithstanding this, the T2 in the non iron-loaded heart compares well with the expected in vivo value, and although T2 is observed to change over time, the effect is modest. With sequences which use a train of echoes to measure T2 (Carr-PurcellMeiboom-Gill sequences), the T2 value is dependent on the inter-echo spacing and the derived T2 may be higher than that measured using single spin-echo sequences [49]. This effect should not be as pronounced with the fast spin echo technique we have used. Unfortunately, the difficulty with measurement of $\mathrm{T} 1$ means that we have not been able to produce a meaningful calibration for this parameter. As this study has taken many years to complete, it is unlikely to be easily repeated in whole human hearts, especially as the survival of patients with beta thalassaemia is constantly improving and hence transplant or autopsy heart specimens will become less frequently available. Also, we do not have the opportunity to go back and rescan, as the technique for measurement of tissue iron is fully destructive. There is likely to be an imperfect match between the ROIs and the cuts made for the tissue iron samples which could affect $\mathrm{T} 1$ and $\mathrm{T} 2$ but we have tried to minimise this as far as possible.

\section{Conclusions}

Myocardial T2 correlates well with tissue iron concentration with a logarithmic function for best fit. The T2 measured in the non-iron loaded formalin fixed heart compared well with the expected T2 value of normal myocardium in vivo. Further work should establish whether the measurement of myocardial T2 may provide additive 
information to $\mathrm{T}^{*}$ in patients with myocardial siderosis, in particular with regard to iron chemical speciation, and iron mishandling conditions. By contrast, ex-vivo T1 measurements are not reliable and further work will be required before a calibration for $\mathrm{T} 1$ and heart iron concentration can be produced, which takes into account the limitations identified in the current study. An alternative approach would be a direct in-vivo comparison of $\mathrm{T} 1$ against $\mathrm{T} 2$ and $\mathrm{T} 2 *$ as the calibration is now established.

\section{Competing interests}

Dr Carpenter has received honoraria from Novartis, Apotex and Swedish Orphan. Dr He is supported by the British Heart Foundation and is a consultant to Novartis. Professor Porter has received research funding from and served on the speakers' bureau and advisory board for Novartis. Professor Galanello served on the speakers' bureau for Novartis and ApoPharma. Dr Forni has received research funding from Novartis. Professor Fucharoen is a Senior Research Scholar of the Thailand Research Fund. Professor Firmin has received research support from Siemens. Professor Pennell is a consultant to and served on advisory boards or speakers' bureau for Novartis, ApoPharma, AMAG, Shire and Siemens; has received research funding from Novartis and AMAG; and is a director and stockholder for Cardiovascular Imaging Solutions. Professor St Pierre holds shares in and is on the Board of Directors of Resonance Health Ltd, and has received research funding from Novartis. The other authors report no conflicts.

\section{Authors' contributions}

JRP, TH and DNF performed the CMR scans and analysed the CMR data. MR performed the statistical analysis. AF, MH, GB and TGSP performed the ex-vivo iron analysis. PK, JRP, DJP and MS performed the post-mortem heart dissection. LJA, SVN, AJB, JBP, JMW, JCW, GF, GC, GM, and SF recruited patient hearts into the study and contributed critically to the design of the study and the analysis and writing of the paper. DJP raised the funds for the study, was principal architect of the research program, provided critical analysis of the data, and wrote the paper with JRP. All authors read and approved the final manuscript.

\section{Acknowledgements}

We acknowledge the contribution to this work of Professor Renzo Galanello, who is recently deceased. We are indebted to the generosity of the patients and their relatives without whose help we would have been unable to perform this study. We would like to thank Steven Collins for assistance in scanning the ex-vivo hearts and Cathleen Enriquez for her assistance in preparing this manuscript.

\section{Sources of funding}

This work was supported by the National Institutes for Health Research Cardiovascular Biomedical Research Unit of Royal Brompton and Harefield NHS Foundation Trust and Imperial College London. Financial support was also received from the National Institutes of Health through grant number R01 DK066084-01 and from the Australian Research Council through grant number DP0985848.

\section{Author details}

${ }^{1} \mathrm{NIHR}$ Cardiovascular BRU, Royal Brompton Hospital, Sydney Street, London SW3 6NP, UK. ${ }^{2}$ National Heart and Lung Institute, Imperial College London, London, UK. ${ }^{3}$ St George's Hospital NHS Trust, London, UK. ${ }^{4}$ University College Hospitals NHS Trust, London, UK. ${ }^{5}$ Children's Hospital Los Angeles, California, USA. ${ }^{6}$ Ospedali Galliera di Genova, Genoa, Italy. ${ }^{7}$ Azienda Ospedaliera Brotzu, Cagliari, Italy. ${ }^{8}$ Mahidol University, Puttamonthon Nakornpathom, Thailand.

${ }^{9}$ The University of Western Australia, Perth, Australia.
Received: 22 October 2013 Accepted: 31 July 2014

Published: 12 August 2014

\section{References}

1. Anderson LJ, Westwood MA, Holden S, Davis B, Prescott E, Wonke B, Porter JB, Walker JM, Pennell DJ. Myocardial iron clearance during reversal of siderotic cardiomyopathy with intravenous desferrioxamine: a prospective study using $\mathrm{T} 2{ }^{*}$ cardiovascular magnetic resonance. $\mathrm{Br} J$ Haematol. 2004; 127:348-55.

2. Miskin H, Yaniv I, Berant M, Hershko C, Tamary H. Reversal of cardiac complications in thalassemia major by long-term intermittent daily intensive iron chelation. Eur J Haematol. 2003; 70:398-403.

3. Anderson LJ, Holden S, Davis B, Prescott E, Charrier CC, Bunce NH, Firmin DN, Wonke B, Porter J, Walker JM, Pennell DJ. Cardiovascular T2-star (T2*) magnetic resonance for the early diagnosis of myocardial iron overload. Eur Heart J. 2001; 23:2171-9.

4. Nienhuis AW, Griffith P, Strawczynski H, Henry W, Borer J, Leon M, Anderson WF. Evaluation of cardiac function in patients with thalassemia major. Ann N Y Acad Sci. 1980; 344:384-96.

5. Westwood MA, Anderson LJ, Firmin DN, Gatehouse PD, Lorenz CH, Wonke B, Pennell DJ. Interscanner reproducibility of cardiovascular magnetic resonance T2* measurements of tissue iron in thalassemia. J Magn Reson Imaging. 2003; 18:616-20.

6. Westwood M, Anderson LJ, Firmin DN, Gatehouse PD, Charrier CC, Wonke B, Pennell DJ. A single breath-hold multiecho T2* cardiovascular magnetic resonance technique for diagnosis of myocardial iron overload. J Magn Reson Imaging. 2003; 18:33-9.

7. Tanner MA, He T, Westwood MA, Firmin DN, Pennell DJ. Thalassemia International Federation Heart T2* Investigators. Multi-center validation of the transferability of the magnetic resonance $T 2 *$ technique for the quantification of tissue iron. Haematologica. 2006; 91:1388-91.

8. Carpenter JP, He T, Kirk P, Roughton M, Anderson LJ, de Noronha SV, Sheppard MN, Porter JB, Walker JM, Wood JC, Galanello R, Forni G, Catani G, Matta G, Fucharoen S, Fleming A, House MJ, Black G, Firmin DN, St Pierre TG, Pennell DJ. On T2* magnetic resonance and cardiac iron. Circulation. 2011; 123:1519-28.

9. Kirk P, Roughton M, Porter JB, Walker JM, Tanner MA, Patel J, Wu D, Taylor J, Westwood MA, Anderson LJ, Pennell DJ. Cardiac T2* magnetic resonance for prediction of cardiac complications in thalassemia major. Circulation. 2009; 120:1961-8.

10. Telfer PT, Prestcott E, Holden S, Walker M, Hoffbrand AV, Wonke B. Hepatic iron concentration combined with long-term monitoring of serum ferritin to predict complications of iron overload in thalassaemia major. $\mathrm{Br} J$ Haematol. 2000; 110:971-7.

11. Leonardi B, Margossian R, Colan SD, Powell AJ. Relationship of magnetic resonance imaging estimation of myocardial iron to left ventricular systolic and diastolic function in thalassemia. JACC Cardiovasc Imaging. 2008; 1:572-8.

12. Fitchett DH, Coltart DJ, Littler WA, Leyland MJ, Trueman T, Gozzard DI, Peters TJ. Cardiac involvement in secondary haemochromatosis: a catheter biopsy study and analysis of myocardium. Cardiovasc Res. 1980; 14:719-24.

13. Olson LJ, Edwards WD, McCall JT, Ilstrup DM, Gersh BJ. Cardiac iron deposition in idiopathic hemochromatosis: histologic and analytic assessment of 14 hearts from autopsy. J Am Coll Cardiol. 1987; 10:1239-43.

14. Olson LJ, Edwards WD, Holmes DR Jr, Miller FA Jr, Nordstrom LA, Baldus WP. Endomyocardial biopsy in hemochromatosis: clinicopathologic correlates in six cases. J Am Coll Cardiol. 1989; 13:116-20.

15. Modell B, Khan M, Darlison M. Survival in beta thalassaemia major in the UK: data from the UK Thalassaemia Register. Lancet. 2000; 355:2051-2.

16. Modell B, Khan M, Darlison M, Westwood MA, Ingram D, Pennell DJ. Improved survival of thalassaemia major in the UK and relation to $\mathrm{T}^{*}$ cardiovascular magnetic resonance. J Cardiovasc Magn Reson. 2008; 10:42.

17. Wood JC, Otto-Duessel M, Aguilar M, Nick H, Nelson MD, Coates TD, Pollack H, Moats R. Cardiac iron determines cardiac T2* ${ }^{*}$ T2, and T1 in the gerbil model of iron cardiomyopathy. Circulation. 2005; 112:535-43.

18. St Pierre TG, Clark PR, Chua-anusorn W, Fleming AJ, Jeffrey GP, Olynyk JK, Pootrakul P, Robins $E$, Lindeman R. Noninvasive measurement and imaging of liver iron concentrations using proton magnetic resonance. Blood. 2005; 105:855-61. 
19. Wood JC, Enriquez C, Ghugre N, Tyzka JM, Carson S, Nelson MD, Coates TD. MRI R2 and R2* mapping accurately estimates hepatic iron concentration in transfusion-dependent thalassemia and sickle cell disease patients. Blood. 2005; 106:1460-5.

20. Piechnik SK, Ferreira VM, Dall'Armellina E, Cochlin LE, Greiser A, Neubauer S, Robson MD. Shortened Modified Look-Locker Inversion recovery (ShMOLLI) for clinical myocardial T1-mapping at 1.5 and $3 \mathrm{~T}$ within a 9 heartbeat breathhold. J Cardiovasc Magn Reson. 2010; 12:69.

21. Verhaert D, Thavendiranathan P, Giri S, Mihai G, Rajagopalan S, Simonetti OP, Raman SV. Direct T2 quantification of myocardial edema in acute ischemic injury. JACC Cardiovasc Imaging. 2011; 4:269-78.

22. Cerqueira MD, Weissman NJ, Dilsizian V, Jacobs AK, Kaul S, Laskey WK Pennell DJ, Rumberger JA, Ryan T, Verani MS, American Heart Association Writing Group on Myocardial Segmentation and Registration for Cardiac Imaging. Standardized myocardial segmentation and nomenclature for tomographic imaging of the heart: a statement for healthcare professionals from the Cardiac Imaging Committee of the Council on Clinical Cardiology of the American Heart Association. Circulation. 2002; 105:539-42.

23. He T, Gatehouse PD, Kirk P, Mohiaddin RH, Pennell DJ, Firmin DN. Myocardial T2* measurement in iron-overloaded thalassemia: an ex vivo study to investigate optimal methods of quantification. Magn Reson Med. 2008; 60:350-6.

24. Collins W, Taylor WH. Determination of iron in cardiac and liver tissues by plasma emission spectroscopy. Ann Clin Biochem. 1987; 24:482-7.

25. Abbruzzese G, Cossu G, Balocco M, Marchese R, Murgia D, Melis M, Galanello R, Barella S, Matta G, Ruffinengo U, Bonuccelli U, Forni GL. A pilot trial of deferiprone for neurodegeneration with brain iron accumulation. Haematologica. 2011; 96:1708-11.

26. Ghugre NR, Enriquez CM, Gonzalez I, Nelson MD Jr, Coates TD, Wood JC. MRI detects myocardial iron in the human heart. Magn Reson Med. 2006; 56:681-6.

27. Mavrogeni SI, Markussis V, Kaklamanis L, Tsiapras D, Paraskevaidis I, Karavolias G, Karagiorga M, Douskou M, Cokkinos DV, Kremastinos DT. A comparison of magnetic resonance imaging and cardiac biopsy in the evaluation of heart iron overload in patients with beta-thalassemia major. Eur J Haematol. 2005; 75:241-7.

28. Garbowski MW, Carpenter JP, Smith G, Roughton M, Alam MH, He T, Pennell DJ, Porter JB. Biopsy-based calibration of $\mathrm{T} 2 *$ magnetic resonance for estimation of liver iron concentration and comparison with R2 Ferriscan. J Cardiovasc Magn Reson. 2014; 16:40.

29. He T, Gatehouse PD, Anderson LJ, Tanner M, Keegan J, Pennell DJ, Firmin DN. Development of a novel optimized breathhold technique for myocardial T2 measurement in thalassemia. J Magn Reson Imaging. 2006; 24:580-5.

30. He T, Kirk P, Firmin DN, Lam WM, Chu WC, Au WY, Chan GC, Tan RS, Ng I, Biceroglu S, Aydinok Y, Fogel MA, Cohen AR, Pennell DJ. Multi-center transferability of a breath-hold T2 technique for myocardial iron assessment. J Cardiovasc Magn Reson. 2008; 10:11.

31. Jensen PD, Jensen FT, Christensen $T$, Heickendorff L, Jensen LG, Ellegaard J. Indirect evidence for the potential ability of magnetic resonance imaging to evaluate the myocardial iron content in patients with transfusional iron overload. Magma. 2001; 12:153-66.

32. Messroghli DR, Plein S, Higgins DM, Walters K, Jones TR, Ridgway JP, Sivananthan MU. Human myocardium: single-breath-hold MR T1 mapping with high spatial resolution-reproducibility study. Radiology. 2006; 238:1004-12.

33. Feng $Y$, He T, Carpenter JP, Jabbour A, Alam MH, Gatehouse PD, Greiser A, Messroghli D, Firmin DN, Pennell DJ. In vivo comparison of myocardial T1 with T2 and T2* in thalassaemia major. J Magn Reson Imaging. 2013; 38:588-93.

34. Kamman RL, Go KG, Brouwer W, Berendsen HJ. Nuclear magnetic resonance relaxation in experimental brain edema: effects of water concentration, protein concentration, and temperature. Magn Reson Med. 1988; 6:265-74.

35. He T, Smith G, Carpenter JP, Mohiaddin R, Pennell DJ, Firmin D. A phantom study of temperature-dependent MRI T2* measurement. J CardiovasC Magn Reson. 2009; 11(Suppl 1):147.

36. Wacker CM, Bock M, Hartlep AW, Beck G, van Kaick G, Ertl G, Bauer WR Schad LR. Changes in myocardial oxygenation and perfusion under pharmacological stress with dipyridamole: assessment using $\mathrm{T} 2{ }^{*}$ and $\mathrm{T} 1$ measurements. Magn Reson Med. 1999; 41:686-95.
37. Krombach GA, Hahn C, Tomars M, Buecker A, Grawe A, Günther RW, Kühl HP. Cardiac amyloidosis: MR imaging findings and T1 quantification, comparison with control subjects. J Magn Reson Imaging. 2007; 25:1283-7.

38. Hsu JC, Johnson GA, Smith WM, Reimer KA, Ideker RE. Magnetic resonance imaging of chronic myocardial infarcts in formalin-fixed human autopsy hearts. Circulation. 1994; 89:2133-40.

39. Barry M. Liver iron concentration, stainable iron, and total body storage iron. Gut. 1974; 15:411-5.

40. Koizumi N, Hatayama F, Sumino K. Problems in the analysis of cadmium in autopsied tissues. Environ Res. 1994; 64:192-8.

41. Olynyk JK, O'Neill R, Britton RS, Bacon BR. Determination of hepatic iron concentration in fresh and paraffin-embedded tissue: diagnostic implications. Gastroenterology. 1994; 106:674-7.

42. Chua-anusorn W, Webb J, Macey DJ, Pootrakul P, St Pierre TG. The effect of histological processing on the form of iron in iron-loaded human tissues. Biochim Biophys Acta. 1997; 1360:255-61.

43. Hosch W, Bock M, Libicher M, Ley S, Hegenbart U, Dengler TJ, Katus HA, Kauczor HU, Kauffmann GW, Kristen AV. MR-relaxometry of myocardial tissue: significant elevation of T1 and T2 relaxation times in cardiac amyloidosis. Invest Radiol. 2007; 42:636-42.

44. Saryan LA, Hollis DP, Economou JS, Eggleston JC. Nuclear magnetic resonance studies of cancer. IV. Correlation of water content with tissue relaxation times. J Natl Cancer Inst. 1974; 52:599-602.

45. Kamman RL, Go KG, Stomp GP, Hulstaert CE, Berendsen HJ. Changes of relaxation times $\mathrm{T} 1$ and $\mathrm{T} 2$ in rat tissues after biopsy and fixation. Magn Reson Imaging. 1985; 3:245-50.

46. Tovi M, Ericsson A. Measurements of $\mathrm{T} 1$ and $\mathrm{T} 2$ over time in formalin-fixed human whole-brain specimens. Acta Radiol. 1992; 33:400-4.

47. Thickman DI, Kundel HL, Wolf G. Nuclear magnetic resonance characteristics of fresh and fixed tissue: the effect of elapsed time. Radiology. 1983; 148:183-5.

48. Yong-Hing CJ, Obenaus A, Stryker R, Tong K, Sarty GE. Magnetic resonance imaging and mathematical modeling of progressive formalin fixation of the human brain. Magn Reson Med. 2005; 54:324-32.

49. Jensen $\mathrm{JH}$, Chandra R. NMR relaxation in tissues with weak magnetic inhomogeneities. Magn Reson Med. 2000; 44:144-56.

\section{doi:10.1186/s12968-014-0062-4}

Cite this article as: Carpenter et al:: Calibration of myocardial T2 and T1 against iron concentration. Journal of Cardiovascular Magnetic Resonance 2014 16:62.

\section{Submit your next manuscript to BioMed Central and take full advantage of:}

- Convenient online submission

- Thorough peer review

- No space constraints or color figure charges

- Immediate publication on acceptance

- Inclusion in PubMed, CAS, Scopus and Google Scholar

- Research which is freely available for redistribution

Submit your manuscript at www.biomedcentral.com/submit
C) Biomed Central 